\title{
Effect of Leaf Surface Waxes on Leaf Colonization by Pantoea agglomerans and Clavibacter michiganensis
}

\author{
Lise M. Marcell and Gwyn A. Beattie \\ lowa State University, Department of Plant Pathology, Ames 50011-3211, U.S.A. \\ Submitted January 30 2002. Accepted August 132002.
}

To evaluate the influence of leaf cuticular waxes on bacterial colonization of leaves, bacterial colonization patterns were examined on four glossy maize (Zea mays $\mathrm{L}$.) mutants that were altered in their cuticular wax biosynthesis. Mutant $g l 3$ was indistinguishable from the wild-type maize in its ability to foster colonization by the two bacterial species, Pantoea agglomerans and Clavibacter michiganensis subsp. nebraskensis. In contrast, the other three mutants supported the development of populations that significantly differed in size from those on the wild type. Mutant gl5 gl20 supported smaller populations of $P$. agglomerans, but not $C$. michiganensis, while mutant gll supported larger populations of $C$. michiganensis but not $P$. agglomerans. Mutant gl4 supported larger populations of both bacterial species. The exceptional ability of mutant gl4 to support bacterial colonization was hypothesized to result from the lower density of the crystalline waxes on gl4 than on the wild type, because a reduced crystal density could promote capillary water movement and water trapping among the wax crystals. This hypothesis was supported by the demonstration that the mechanical introduction of gaps among the wax crystals of the wild-type leaves resulted in the establishment of larger $P$. agglomerans populations on the altered leaves. These results provide the first direct evidence that leaf surface waxes affect bacterial leaf colonization at various stages of colonization and in a bacterial speciesdependent manner.

Additional keywords: cuticle, glossy mutant, hydrophobicity, phyllosphere, wettability.

Aerial plant leaves commonly are colonized by large bacterial populations. Leaf-associated bacterial communities can include members that cause disease, induce frost injury, alter plant growth through phytohormone production, protect plants from disease or frost injury, or fix atmospheric nitrogen. For a strain that has one or more of these abilities, a larger population size is likely related to the strain's effect on plant or ecosystem health.

Although many studies have examined the influence of environmental conditions and bacterial traits on bacterial colonization of leaves (Beattie and Lindow 1999; Brandl and Lindow 1998; Hirano and Upper 2000; Poplawsky and Chun 1998; Sundin and Jacobs 1999; Yu et al. 1999), few have ex-

Corresponding author: Gwyn A. Beattie; Telephone: 1-515-294-5571; Fax: 1-515-294-6019; E-mail: gbeattie@ iastate.edu.

Current address of Lisa M. Marcell: Plant Transformation Facility, Iowa State University, Ames, IA 50011, U.S.A. amined the influence of specific plant traits. Some general traits, including plant species, age, disease resistance, and nutrition, can each influence bacterial population sizes on leaves, but how these influences are mediated is not known. The presence of leaf trichomes was found to favor bacterial colonization based on the fact that wild-type tomato plants supported larger populations of Pseudomonas syringae than trichomedeficient mutants (Schneider and Grogan 1977). The waxy plant cuticle also may influence bacterial colonization. Correlative studies indicate that "nonwaxy" plants foster larger populations of bacteria than plants with large amounts of cuticular waxes (O'Brien and Lindow 1989). Also, a brief report by Haefele and Lindow (1984) indicated that a cuticular waxdeficient maize mutant supported larger populations of epiphytic ice nucleation active bacteria than did wild-type plants and that plants that were altered in their cuticular waxes using an herbicide or physical abrasion supported larger populations than did untreated plants. These results indicate that, at least under some conditions, the presence of intact wild-type cuticular waxes can hinder the establishment of large bacterial populations. The effects of specific cuticular properties on colonization have been examined for several phytopathogenic fungi (Beattie 2002). For example, leaf surface hydrophobicity has been shown to enhance spore adhesion and appressorium differentiation (Clement et al. 1994; Mercure et al. 1994), whereas leaf surface topography can influence hyphal growth orientation (Hoch et al. 1987).

The plant cuticle is likely to be a defining feature of the leaf surface as a habitat for colonization following bacterial immigration. The plant cuticle functions as a physical barrier, preventing water and solute loss from plant leaves. It is composed of soluble waxes both infused in a matrix of insoluble polymers and extruded onto the matrix surface. The extruded waxes, known as the epicuticular waxes, form a relatively smooth layer on some plant species and a stand of crystals on others, such as maize (Jeffree 1996). The chemical composition and quantity of the waxes, as well as the morphology and density of the epicuticular crystalline waxes, are distinct for each plant species and often differ with plant growth stage and environment (Bianchi 1995; Jenks and Ashworth 1999). $\mathrm{Mu}-$ tants that are altered in the biosynthesis of their cuticular waxes have been identified in several plant species. These mutants usually have been identified based on their increased retention of water after spraying, although mutants of some plant species have been identified based on their visibly glossy leaves (Jenks and Ashworth 1999). These mutants often are referred to as glossy mutants.

To study the influence of the cuticle on bacterial colonization of the phyllosphere, we employed a collection of maize (Zea mays L.) glossy mutants (Schnable et al. 1994). These mutants are altered in the biosynthesis of their juvenile waxes 
(i.e., the waxes on their first five to seven leaves) (Bianchi et al. 1985). The four glossy mutants employed in this study were nonallelic gene mutants that had homozygous recessive alterations at either a single locus ( $g l l, g l 3$, and $g l 4)$ or at two distinct loci $(\mathrm{gl} / 5 \mathrm{gl} 20)$. In a recent study (Beattie and Marcell 2002b), we demonstrated that these mutants each exhibited a unique combination of the following traits: the wettability of the leaves, the mass of waxes produced, the percentage of surface area covered by epicuticular crystalline waxes, and the density and morphology of the crystalline waxes. The objective of this study was to determine if the cuticular characteristics of these four glossy mutants influenced the leaf surface as a habitat for colonization by two bacterial species, the saprophyte Pantoea agglomerans and the pathogen Clavibacter michiganensis subsp. nebraskensis. We hypothesized that mutant gl4 would support populations that are similar in size to those on the wild type because, among the mutants, its leaf surface properties are most similar to those of the wild type. We also hypothesized that mutant $g l l$ would foster the largest bacterial populations because it produces the least amount of cuticular wax of the mutants examined and, thus, should have the greatest level of nutrient exudation; and is the most wettable and, thus, should have the widest distribution of water and nutrients. We present evidence that the leaf surface waxes of maize can influence bacterial leaf colonization, but do so in ways that we did not predict.

\section{RESULTS}

\section{Bacterial retention on the glossy mutants.}

Immediately following spray inoculation with suspensions of $10^{7}$ or $10^{8}$ cells per ml, the glossy mutants retained significantly larger numbers of $P$. agglomerans strain BRT98 than the wild type did (Fig. 1). Similarly, the glossy mutants retained significantly larger numbers of $C$. michiganensis subsp. nebraskensis strain GH2390 than the wild type did. Mutants $\mathrm{gll}, \mathrm{gl} 5 \mathrm{gl20}$, and $\mathrm{gl3}$ retained similar numbers of bacteria, but retained greater numbers than $g l 4$ did. Based on a plot of the number of bacteria retained as a function of the leaf surface hydrophobicity (Fig. 1), which was determined in a previous study (Beattie and Marcell 2002b), an increase in the hydrophobicity that was reflected in an increase in the contact angle from $112^{\circ}$ to $140^{\circ}$ had no effect on retention. In contrast, an increase from $140^{\circ}$ to $142^{\circ}$ was associated with a significant decrease in the number of bacteria retained, and a further increase to $147^{\circ}$ was associated with a further decrease in retention (Fig. 1).

\section{Population dynamics of $P$. agglomerans BRT98 on the glossy mutants.}

To evaluate the bacterial population dynamics on the wild type and maize glossy mutants, the density of the bacterial suspension that was applied to each genotype was selected to promote the retention of approximately $10^{6}$ cells per $\mathrm{g}$ of leaf.

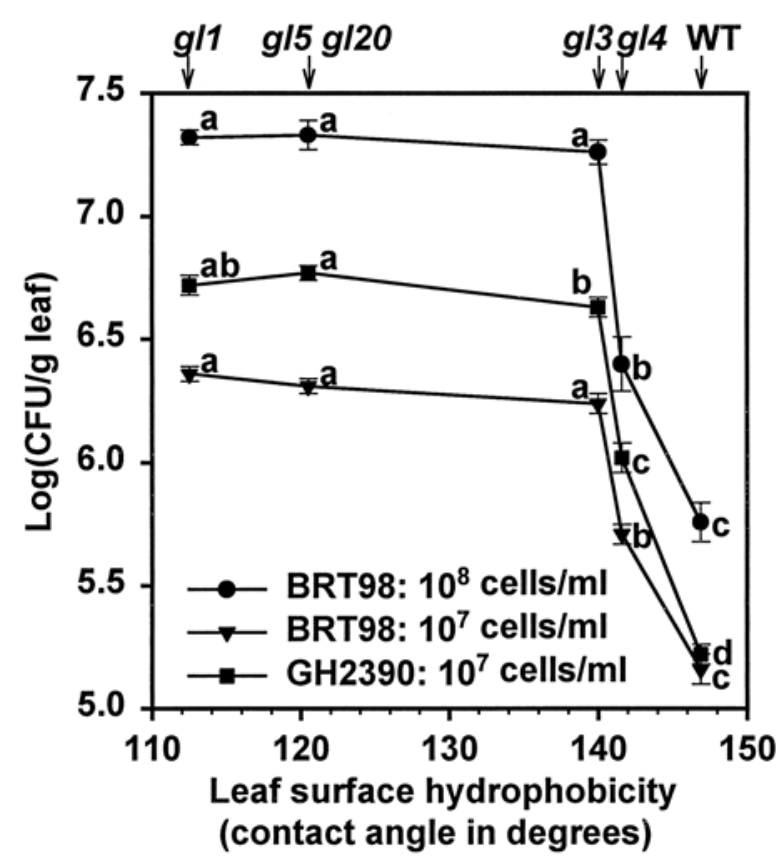

Fig. 1. Relation between maize leaf surface hydrophobicity and the population sizes of Pantoea agglomerans BRT98 and Clavibacter michiganensis subsp. nebraskensis GH2390 immediately following spray inoculation. The mean contact angle measurement of each genotype (i.e., the angle at which a sessile water droplet contacted the leaf surface) reflects the leaf surface hydrophobicity and was determined in a previous study. The inocula consisted of cell suspensions of either $10^{8}$ or $10^{7}$ cells $/ \mathrm{ml}$, as indicated. For each inoculum, the data points followed by the same letter do not differ significantly from one another based on a Fisher's least significant difference test $(P<0.0001)$. A replicate experiment of the BRT98 inoculum $\left(10^{8}\right.$ cells $\left./ \mathrm{ml}\right)$ gave similar results. Each value represents the mean $\log (\mathrm{CFU} / \mathrm{g}$ leaf $) \pm$ standard error of 12 samples.

Table 1. Significance of the differences in the population sizes of Pantoea agglomerans BRT98 and Clavibacter michiganensis subsp. nebraskensis GH2390 on each glossy mutant versus on the wild type

\begin{tabular}{|c|c|c|c|c|c|c|c|c|}
\hline \multirow[b]{2}{*}{ Significance of the: } & \multicolumn{4}{|c|}{ P. agglomerans BRT98 } & \multicolumn{4}{|c|}{ C. michiganensis subsp. nebraskensis $\mathbf{G H 2 3 9 0}^{\mathrm{b}}$} \\
\hline & $g l 1$ & $g l 3$ & $g l 4$ & $g l 5 g l 20$ & $g l 1$ & $g l 3$ & $g l 4$ & $g l 5 g l 20$ \\
\hline $\begin{array}{l}\text { Differences among } \\
\text { experiments }\end{array}$ & 0.1 & 0.1 & 0.004 & 0.6 & 0.01 & $<0.0001$ & 0.0002 & 0.001 \\
\hline $\begin{array}{l}\text { Experiment-genotype } \\
\text { interaction }\end{array}$ & 0.0005 & 0.04 & 0.1 & 0.6 & 0.8 & 0.3 & 0.2 & 0.7 \\
\hline $\begin{array}{l}\text { Differences between the } \\
\text { mutant and wild type: }\end{array}$ & & & & & & & & \\
\hline Across experiments & 0.5 & 0.3 & $<0.0001$ & $<0.001$ & $<0.0001$ & 0.95 & $<0.0001$ & 0.2 \\
\hline Within experiment 1 & 0.3 & 0.02 larger & 0.0001 larger & 0.02 smaller & 0.005 larger & 0.3 & 0.001 larger & 0.2 \\
\hline Within experiment 2 & 0.001 smaller & 0.2 & 0.06 (larger) & 0.006 smaller & 0.004 larger & 0.3 & 0.002 larger & 0.3 \\
\hline Within experiment 3 & 0.1 & 0.4 & 0.06 (larger) & 0.0008 smaller & 0.02 larger & 0.9 & 0.3 & 0.9 \\
\hline
\end{tabular}

a Values shown are the $P$ values resulting from a two-factor analysis of variance (ANOVA) of the BRT98 population sizes on the leaves of the wild type and the indicated mutant in the three replicate experiments P1, P2, and P3, which were designated experiment 1, 2, and 3, respectively, after normalization of each population to the mean $\log (\mathrm{CFU} / \mathrm{g})$ at $0 \mathrm{~h}$. In the two-factor ANOVA, the factors were experiment and genotype, with genotype referring to the mutant and the wild type. Within an experiment, values shown are the $P$ values resulting from an ANOVA of the population sizes on the wild type and the indicated mutant. Each test was performed on the population sizes at all sampling times after $0 \mathrm{~h}$. For comparisons that were significant, the relative size of the populations on the mutant compared to on the wild type is stated.

b The values shown are as described above, except the two-factor ANOVAs were performed on the data in the three replicate experiments C1, C2, and C3, which were designated experiment 1,2 , and 3 , respectively. 
Three replicate experiments were performed to test for differences in the population dynamics of P. agglomerans BRT98 on the mutants versus on the wild type. Although the population dynamics of BRT98 on mutants $g l l$ and $g l 3$ differed from those on the wild type in individual experiments (Table 1), the relative population dynamics did not exhibit similar trends from experiment to experiment. Furthermore, an analysis of the data in the three replicate experiments indicated that the BRT98 populations on mutants $g l l$ and $g l 3$ did not differ significantly in size from those on the wild type when the populations at 24 to $96 \mathrm{~h}$ were pooled and compared (Table 1).

Strain BRT98 consistently established larger populations on gl4 than on the wild type in all three experiments performed. The population dynamics in experiment P1 are shown in Figure 2A. Although the BRT98 populations on $g l 4$ at 24 to $96 \mathrm{~h}$ were significantly larger than those on the wild type at only a $P=0.06$ level in experiments 2 and 3 , an analysis of the data in the three replicate experiments indicated that the difference in BRT98 population sizes on $g l 4$ and on the wild type were significant (Table 1). In an additional experiment performed under similar conditions but with an increased sample size (14 to 25 samples) at each time point, the BRT98 populations on gl4 were slightly but significantly smaller than those on the wild type immediately following inoculation but were significantly larger than those on the wild type at each subsequent time point $(P=0.0001)$ (data not shown). A major difference in the BRT98 populations dynamics on $g l 4$ and the wild type was in the survival in the $24 \mathrm{~h}$ following inoculation; a greater proportion of the BRT98 population survived on gl4 than on the wild type during this period. Specifically, the proportional

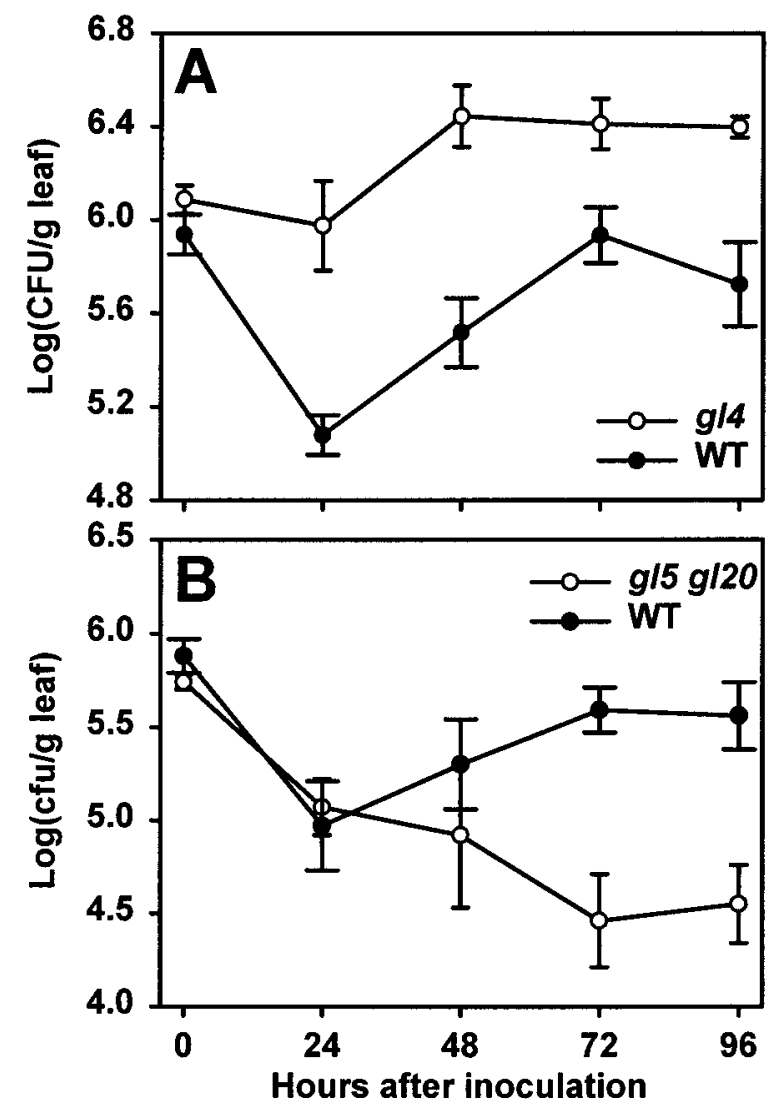

Fig. 2. Population dynamics of Pantoea agglomerans BRT98 on maize leaves at $95 \%$ relative humidity. A, Mutant $g l 4$ and the wild type (WT) in experiment P1. B, Mutant gl5 gl2O and the wild type in experiment P3. Each value represents the mean $\log (\mathrm{CFU} / \mathrm{g}$ leaf $) \pm$ standard error of 12 samples. decrease in the population size between 0 and $24 \mathrm{~h}$ in the three experiments ranged from 1.3- to 5-fold on gl4 but from 7- to 11 -fold on the wild type. Similarly, in the additional experiment performed, BRT98 exhibited a population decrease of 1.8-fold on gl4 and 8-fold on the wild type between 0 and 24 h. In fact, the size of the BRT98 population decrease was smaller on gl4 than on each of the other mutants, as well, in the three experiments.

The BRT98 populations were consistently significantly smaller on $g l 5$ gl20 than on the wild type (Table 1). A major difference in the population dynamics on $\mathrm{gl} 5 \mathrm{gl} 20$ versus on the wild type was not in the survival in the $24 \mathrm{~h}$ following inoculation but rather in the size of the populations established after $24 \mathrm{~h}$ (Fig. 2B). Although the BRT98 populations did not increase after inoculation onto $\mathrm{gl} 5 \mathrm{gl} 20$ in experiment P3 (Fig. 2B), they did exhibit moderate increases in the other two experiments (data not shown).

\section{Population dynamics of $C$. michiganensis GH2390 on the glossy mutants.}

Three replicate experiments were performed to test for differences in the population dynamics of $C$. michiganensis subsp. nebraskensis GH2390 on the mutants versus on the wild type. GH2390 established significantly larger populations on $g l l$ and on gl4 than on the wild type (Table 1). These differences were observed in all three of the experiments, with the exception of gl4 in experiment C3 (Table 1). Although GH2390 exhibited slightly better survival in the $24 \mathrm{~h}$ following inoculation on gll and gl4 than on the wild type, a more noticeable difference in the dynamics of GH2390 on gll and gl4 versus on the wild type was in the growth that occurred after $24 \mathrm{~h}$ postinoculation, as shown for experiment $\mathrm{C} 2$ in Figure 3A. For example, after being normalized to their initial population sizes, the size of the GH2390 populations on $g l l$ were two- to three-fold larger than those on the wild type at $96 \mathrm{~h}$ in all three experiments; whereas, on gl4 at $96 \mathrm{~h}$, they were 5-fold (experiment C3), 7.5-fold (experiment C2), and 10-fold (experiment C1) larger than those on the wild type. Based on the relatively stable population sizes present at 72 and $96 \mathrm{~h}$ on $\mathrm{gll}$ and the wild type, these genotypes appeared to have a carrying capacity of $6 \times 10^{5}$ to $2 \times 10^{6}$ cells per $g$ of leaf and $2 \times 10^{5}$ to $1 \times 10^{6}$ cells/g of leaf, respectively. In contrast, the population sizes on gl4 still appeared to be rapidly increasing at $96 \mathrm{~h}$ in all three experiments, indicating that the carrying capacity of $\mathrm{gl} 4$ for $\mathrm{GH} 2390$ was greater than $3 \times 10^{6}$ to $2 \times 10^{7}$ cells per $g$ of leaf.

The size of the GH2390 populations on mutants $g l 3$ and $g l 5$ gl20 did not differ significantly from those on the wild type in any of the three experiments (Table 1). Interestingly, the size of the GH2390 population decrease in the $24 \mathrm{~h}$ following inoculation was consistently larger, and often significantly larger, on the wild type than on each of the mutants. For example, the GH2390 populations decreased 13-fold on the wild type and 6- to 8-fold on the mutants in experiment $\mathrm{C} 1$, and 22- to 29-fold on the wild type and 4- to 19-fold on the mutants in the other two experiments. This observation suggests that the wild type provided a habitat that was particularly unconducive to GH2390 survival following inoculation. The improved survival on the glossy mutants in this period, however, did not result in the subsequent presence of larger populations on mutants $g l 3$ and $g l 5 g l 20$ than on the wild type.

\section{Investigation into the mechanism by which $g l 4$ enhances the population sizes of $P$. agglomerans BRT98.}

To begin to understand the mechanisms by which the glossy mutants affect bacterial colonization, we further examined BRT98 colonization of gl4. The better survival of BRT98 on gl4 than on the wild type in the $24 \mathrm{~h}$ following inoculation 
suggested that BRT98 may have better access to water, and thus reduced death due to desiccation, on gl4 during this period. We subjected plants to conditions that were more severe for bacterial survival (i.e., to $45 \%$ relative humidity [RH] rather than $95 \% \mathrm{RH}$ ) and found that BRT98 exhibited better survival on $g l 4$ than on the wild type even under these conditions (Fig. 4). Specifically, the BRT98 populations decreased 14-fold on the wild type but only six-fold on $\mathrm{gl}$, and this higher survival rate was associated with the subsequent presence of significantly larger populations on $g l 4$ than on the wild type $(P=0.009)$.

We hypothesized that the increased sizes of the BRT98 populations on gl4 relative to on the wild type were related to the reduced density of the epicuticular wax crystals on mutant gl4 (Beattie and Marcell 2002b). To test this hypothesis, we mechanically altered wild-type cuticles by gently stroking the leaf surfaces with cotton-tipped applicator sticks (Q-tips). Scanning electron microscopy images indicated that the epidermal cells on leaves altered in this manner were not damaged, and that the epicuticular wax crystals were removed from localized regions of the leaves (Fig. 5). The mechanically altered leaves supported the development of larger BRT98 populations by $48 \mathrm{~h}$ after inoculation (Fig. 6A). The BRT98 populations (Fig. 6A) were estimated as the sum of the populations that were easily removed from the leaves (i.e., the nonadherent populations) (Fig. 6B) and the adherent populations (Fig. 6C). The difference in the population sizes on the altered and unaltered leaves generally were not significant, probably due to the combination of a relatively high leaf-to-leaf variability and a small sample size; however, the nonadherent populations on the altered leaves were significantly larger than those on the wild type at $96 \mathrm{~h}$ following inoculation $(P=$ 0.006). The BRT98 populations on the altered leaves were larger than those on the wild type only after $24 \mathrm{~h}$ postinoculation. In the period between 48 and $96 \mathrm{~h}$ postinoculation, the total, nonadherent, and adherent BRT98 populations on the altered leaves were 2.5- to 3-fold, 3.2- to 10.6-fold, and 2- to 3.3-fold larger than those on the unaltered wild-type leaves, respectively, relative to their initial population sizes. The magnitude of these increases was in the same range as the increases observed on gl4 relative to on the wild type (Fig. 2, data not shown for the adherent and nonadherent populations on gl4).

\section{DISCUSSION}

In this study, we used maize glossy mutants as a tool to evaluate the influence of leaf surface waxes on colonization by $P$. agglomerans, which is a common saprophyte of plants (Schnabel and Jones 1999; Thompson et al. 1993), and C. michiganensis subsp. nebraskensis, the causal agent of Goss's wilt of maize. The leaf surface properties and composition of the cuticular waxes of these mutants have been described (Beattie and Marcell 2002b; Bianchi et al. 1977, 1978, 1979). Based on the number of backcrosses performed previously, these mutants are 93 to $99 \%$ genetically identical to the wild type; thus, differences in leaf surface properties resulting from the glossy mutations were very likely causal to differences from the wild type in bacterial colonization.

We provide strong evidence in this study that the surface waxes of leaves can affect bacterial leaf colonization, and do so in a bacterial species-dependent manner. Our results confirm those presented by Haefele and Lindow (1984), although the differences in bacterial population size that they observed on a glossy mutant versus the wild type may have resulted largely from differences in bacterial retention during inoculation. In the current study, we characterized the effect of leaf surface waxes specifically on bacterial retention following ap- plication of an aqueous suspension, as well as on subsequent colonization after ensuring that an equal number of bacteria were present initially on each genotype.

In the absence of active adhesion, the number of bacteria that remain on a leaf following waterborne immigration probably is related directly to the volume of water that is retained. We found that, immediately after spraying bacteria onto leaves, the number of bacteria retained was not quantitatively related to the leaf surface hydrophobicity, as reflected in the average angle of contact between a water droplet and a leaf (Bunster et al. 1989; Rentschler 1971). Those genotypes with a contact angle of $112^{\circ}$ to $140^{\circ}$ retained similar numbers of bacteria, while those with a contact angle of greater than $140^{\circ}$ retained smaller numbers of bacteria. Furthermore, the extent to which the contact angle of a genotype was greater than $140^{\circ}$ was inversely correlated with the number of bacteria that it retained (i.e., significantly fewer bacteria were retained by the wild type $\left[147^{\circ}\right]$ than by $\left.g l 4\left[142^{\circ}\right]\right)$. We observed these trends with both $P$. agglomerans and $C$. michiganensis, as well as with Pseudomonas syringae pv. syringae (Marcell 2000). Thus, assuming that contact angles greater than $140^{\circ}$ are associated with water repellency, or the shedding of water (Martin and Juniper 1970; Neinhuis and Barthlott 1997), these results indicate that, following the arrival of an aqueous suspension of bacteria, the number of bacteria that remain on maize leaves that are not water repellent are similar regardless of the extent of the surface hydrophobicity, but the number that remain on waterrepellent leaves depends on the extent of water repellency.

We propose that the distinct properties of the leaf surface waxes of the wild type and glossy mutants influenced bacterial

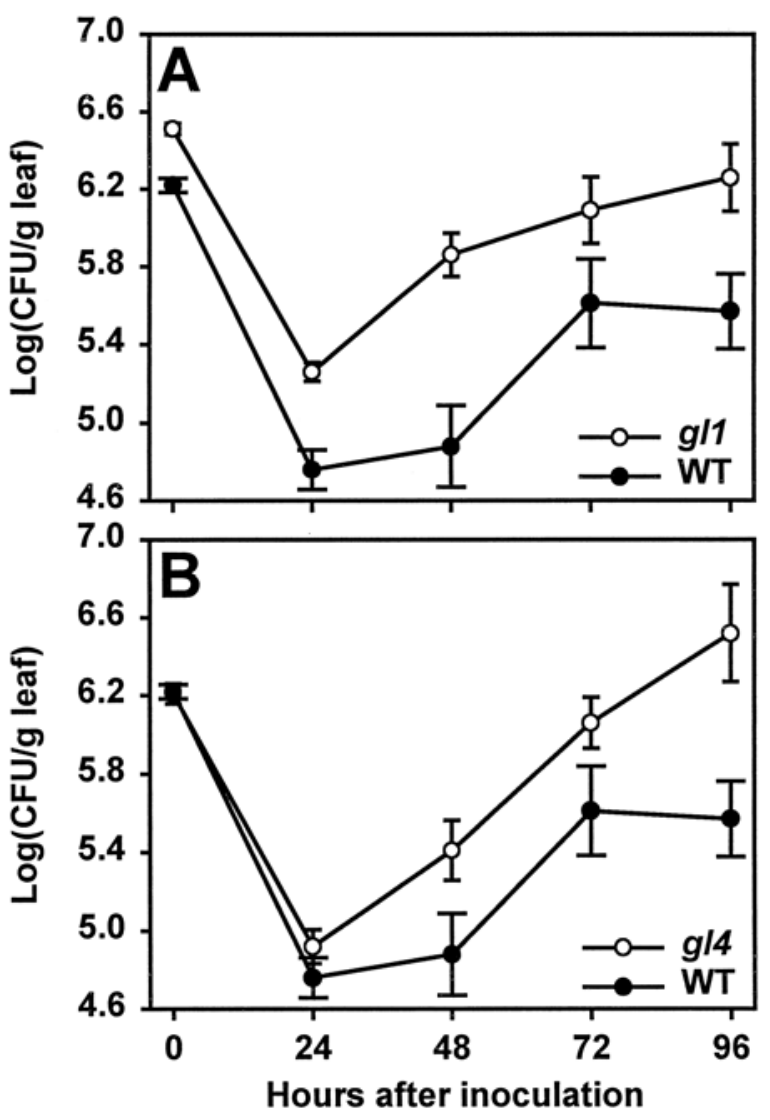

Fig. 3. Population dynamics of Clavibacter michiganensis subsp. nebraskensis GH2390 on maize leaves. A, Mutant $g l 1$ and the wild type (WT) in experiment C2. B, Mutant gl4 and the wild type in experiment $\mathrm{C} 2$. Each value represents the mean $\log (\mathrm{CFU} / \mathrm{g}$ leaf $) \pm$ standard error of 12 samples. 
colonization primarily by influencing the availability of both water and nutrients. The leaf surface waxes, themselves, are unlikely to support growth based on the lack of evidence for bacterial degradation of leaf cuticular waxes. The maize mutants produced crystalline waxes that differ in their morphology and density, with mutants $g l l, g l 5 \mathrm{gl} 20, \mathrm{gl3}$, and $g l 4$ having $12,25,150$, and 128 crystalline waxes per $100 \mu \mathrm{m}^{2}$, respectively, whereas the wild type produces more than 500 (Beattie and Marcell 2002b). The mutants also produce less cuticular wax, with $g l 5$ gl 20 producing $80 \%$ of the amount of wax produced by the wild type, and the others producing only $44 \%(\mathrm{gl}), 38 \%(\mathrm{gl})$, and $12 \%(\mathrm{gll})$ (Beattie and Marcell 2002b). We assume that the plant-derived nutrients arrive on epidermal cells via diffusion through the cuticle, as suggested in previous studies (Fiala et al. 1990; Mercier and Lindow 2000). Thus, following the arrival of an aqueous bacterial suspension onto wild-type leaves, the bacteria probably have limited access to nutrients based on the high density of crystalline waxes causing the aqueous suspension to contact only the tips of the wax crystals (Barthlott and Neinhuis 1997), and the presence of air spaces beneath the suspension hindering the dissolution of the plant-derived nutrients into the suspension. The high density of the crystals would likely continue to inhibit downward capillary flow after the arrival of the bacteria. The bacterial growth that was observed on the wild-type leaves may have occurred in regions with a lower crystal density, such as on the subsidiary cells (Beattie and Marcell 2002b).

The unique ability of mutant $g l 4$ to foster larger populations of both Pantoea agglomerans and $C$. michiganensis was probably due to a unique combination of cuticular traits. We hypothesize that the presence of tall crystals that are similar in structure to those on the wild type and a reduced density of crystals promote the capillary movement of water down to the leaf surface. Such movement would not only facilitate the diffusion of plant-derived nutrients into the water, but also would limit the subsequent evaporation by surrounding the water with wax on several sides. Furthermore, the reduced mass of waxes on gl4 could weaken the cuticle as a barrier to nutrient exudation and, thus, could promote higher concentrations of nutrients on the gl4 surface. Therefore, one explanation for the larger bacterial populations on gl4 is that the bacteria have better access to nutrients and water than on the wild type. This is supported by the improved survival of P. agglomerans on gl4 even under low RH conditions. Alternatively, the altered com-

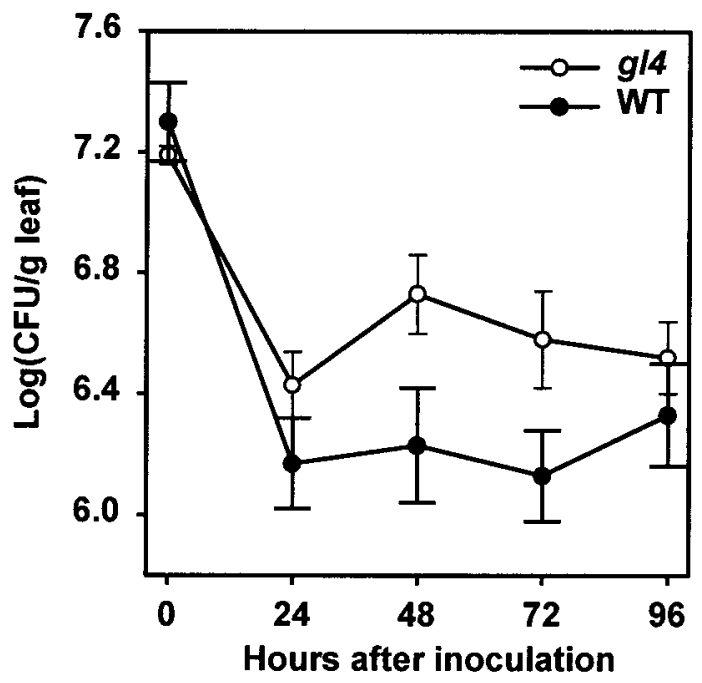

Fig. 4. Population dynamics of Pantoea agglomerans BRT98 on mutant gl4 and the wild type (WT) at $45 \%$ relative humidity. Each value represents the mean $\log (\mathrm{CFU} / \mathrm{g}$ leaf $) \pm$ standard error of 12 samples. position of the waxes on gl4 changed the composition of the exuded nutrients to favor the development of populations of both bacterial species.

We evaluated the hypothesis that a reduction in crystalline wax density could contribute to the ability of maize leaves to foster large P. agglomerans populations. Specifically, we introduced gaps among the crystalline waxes on the wild type, thus effectively reducing the crystal density, and evaluated bacterial colonization of these surface-altered leaves. This leaf treatment resulted in a very clear, localized loss of crystalline waxes in many regions without detectable damage to the plant epidermal cells. These surface-altered leaves supported 1.9- to 2.3-fold larger $P$. agglomerans populations than did wild-type leaves, whereas mutant gl4 supported 2.8- to 4.8-fold larger populations. Thus, the size of the population increase caused by the mechanical alteration was smaller, but in the same general range, as the increase on gl4 relative to on the wild type. These results support the hypothesis that, in a plant with crystalline waxes that are similar in morphology to those of gl4 and the wild type, the density of the wax crystals can influence bacterial leaf colonization.

Mutant $g l 3$ is nearly identical to $g l 4$ in its leaf surface properties (Beattie and Marcell 2002b), but was not similar to gl4 in fostering larger bacterial populations than the wild type. The major difference between mutants $g l 3$ and $g l 4$ is in the morphology of the crystalline waxes; those of $g l 3$ are short and generally globular, whereas those on $\mathrm{gl} 4$ are often tall and wide (Beattie and Marcell 2002b). An inability of the globular waxes to trap water may explain why $g l 3$ was not similar to gl4 in its affect on bacterial colonization.

Although mutant $g l l$ was predicted to favor the development of larger bacterial populations than the wild type, it did so only for $C$. michiganensis. The $C$. michiganensis populations may have been larger due to the presence of a relatively high concentration of nutrients, as could result from the low mass of waxes permitting ample diffusion of nutrients to the surface, or to the widespread distribution of water and nutrients, as would result from a low leaf surface hydrophobicity. Alternatively, the altered composition of the waxes on $g l l$ may have changed the composition of the exuded nutrients to favor the growth of C. michiganensis but not $P$. agglomerans. The widespread distribution of water on $g l l$ could promote a short residence time for the water during a period of evaporation. If $P$. agglomerans is more sensitive to desiccation than $C$. michiganensis, as is commonly believed for gram-negative bacteria relative to gram-positive bacteria, then the inability of gll to foster larger populations of $P$. agglomerans may be due to nutrient-driven increases being negated by desiccation-driven decreases.

Mutant $\mathrm{gl} 5 \mathrm{gl} 20$ was similar to mutant $\mathrm{gll}$ in having a relatively low leaf surface hydrophobicity and a low density of crystalline waxes; however, it produced much more cuticular wax than the other mutants (Beattie and Marcell 2002b). Furthermore, its waxes were uniquely dominated by a chemical component found in only minor quantities in the other mutants (Bianchi et al. 1978). P. agglomerans established populations on $g l 5$ gl20 that were consistently significantly smaller than those on the wild type, and were smaller than those on the other mutants relative to their initial populations. These observations suggest that $P$. agglomerans cells were strongly limited for nutrients on $g l 5 \mathrm{gl} 20$, as would be predicted based on the large mass of cuticular waxes present, or for water under conditions that promote evaporation, as would be predicted based on its low leaf surface hydrophobicity. Alternatively, $P$. agglomerans colonization of $\mathrm{gl} 5 \mathrm{gl} 20$ may have been disfavored by chemicals that were uniquely present on $\mathrm{gl}$ gl 20 or by the nonuniform wax layer that dominates the landscape of $g l 5$ gl20 (Beattie and Marcell 2002b). C. michiganensis coloniza- 
tion of $\mathrm{gl5}$ gl20 was indistinguishable from that of the wild type, possibly due to $C$. michiganensis exhibiting better tolerance to desiccation than $P$. agglomerans, as mentioned above, or due to a better tolerance to a leaf surface chemical that disfavored $P$. agglomerans.

In conclusion, we have provided evidence that the characteristics of a leaf cuticle can influence bacterial colonization of a leaf. An important implication of this finding is that changes in the cuticle may alter the sizes of specific leaf-associated populations, such as those involved in biological control or in the induction of disease or frost injury. Changes in the cuticle of plants can result from air pollution, drought stress, and environmental conditions associated with global warming (Beattie 2002; Jenks and Ashworth 1999), as well as from genetic modification of cuticular waxes (Ohlrogge 1994), such as for enhanced stress resistance or altered ornamental properties. Future studies focused on the mechanistic bases of leaf waxbacterial interactions are required to better predict how specific cuticular changes will affect target bacterial populations.

\section{MATERIALS AND METHODS}

Plant material and plant growth conditions.

Seed of the wild-type Zea mays subsp. mays L. inbred B73 (genotype $G l$ ) were obtained from the North Central Regional Plant Introduction Station (PI 550473; Ames, IA, U.S.A.). B73 is susceptible to Goss's wilt caused by $C$. michiganensis subsp. nebraskensis. The near-isogenic glossy mutants gll, gl3, gl4, and $\mathrm{gl}$ gl20 were obtained from P. S. Schnable at Iowa State University. The leaf surface properties of these mutants have been described (Beattie and Marcell 2002b). These mutants include both spontaneous and chemically induced mutants. For each experiment, three to seven pots (five seeds per pot) of each mutant and the wild type were grown in a 1:2:1 peatperlite-soil potting mixture in a plant growth chamber, as de- scribed previously (Beattie and Marcell 2002b). Plants were used as seedlings at approximately the time of emergence of leaf 4 . The leaf number designations counted the nonleaf coleoptile as 0 .

\section{Bacterial strains and culture media.}

P. agglomerans (formerly Erwinia herbicola) strain BRT98 (Beattie and Marcell 2002a) was resistant to rifampin. Strain BRT98 was grown on one-half strength tryptic soy agar (Microtech Scientific, Orange, CA, U.S.A.) containing rifampin (50 $\mu \mathrm{g} / \mathrm{ml})$. C. michiganensis subsp. nebraskensis strain GH2390 (Beattie and Marcell 2002a) was grown on nutrient broth yeast agar (Vidaver 1967) for preparation of inocula for plants. For enumeration following bacterial recovery from plants, GH2390 was grown on sCNS medium (Beattie and Marcell 2002a). All media contained cycloheximide $(100 \mu \mathrm{g} / \mathrm{ml})$ to inhibit fungal growth. Both strains were grown at $28^{\circ} \mathrm{C}$.

\section{Inoculum preparation and application to plants.}

Bacterial suspensions were prepared by suspending cells grown on solid media in $10 \mathrm{mM}$ potassium phosphate buffer (pH 7) to a density of approximately $10^{10}$ cells $/ \mathrm{ml}$. Cell densities were estimated based on optical density measurements at $600 \mathrm{~nm}\left(\mathrm{OD}_{600}\right)$ of cell suspension dilutions and standard curves relating $\mathrm{OD}_{600}$ to cell concentration. Each pot of plants was inoculated by applying approximately $18 \mathrm{ml}$ of inoculum with a sprayer.

\section{Evaluation of bacterial retention to leaves.}

The retention of $P$. agglomerans strain BRT98 to leaves was examined following inoculation with a suspension of $10^{8}$ cells per $\mathrm{ml}$; this experiment was repeated twice. In another experiment, the retention of $P$. agglomerans BRT98 and C. michiganensis subsp. nebraskensis strain GH2390 was compared following inoculation with cell suspensions of $10^{7}$ cells per $\mathrm{ml}$.
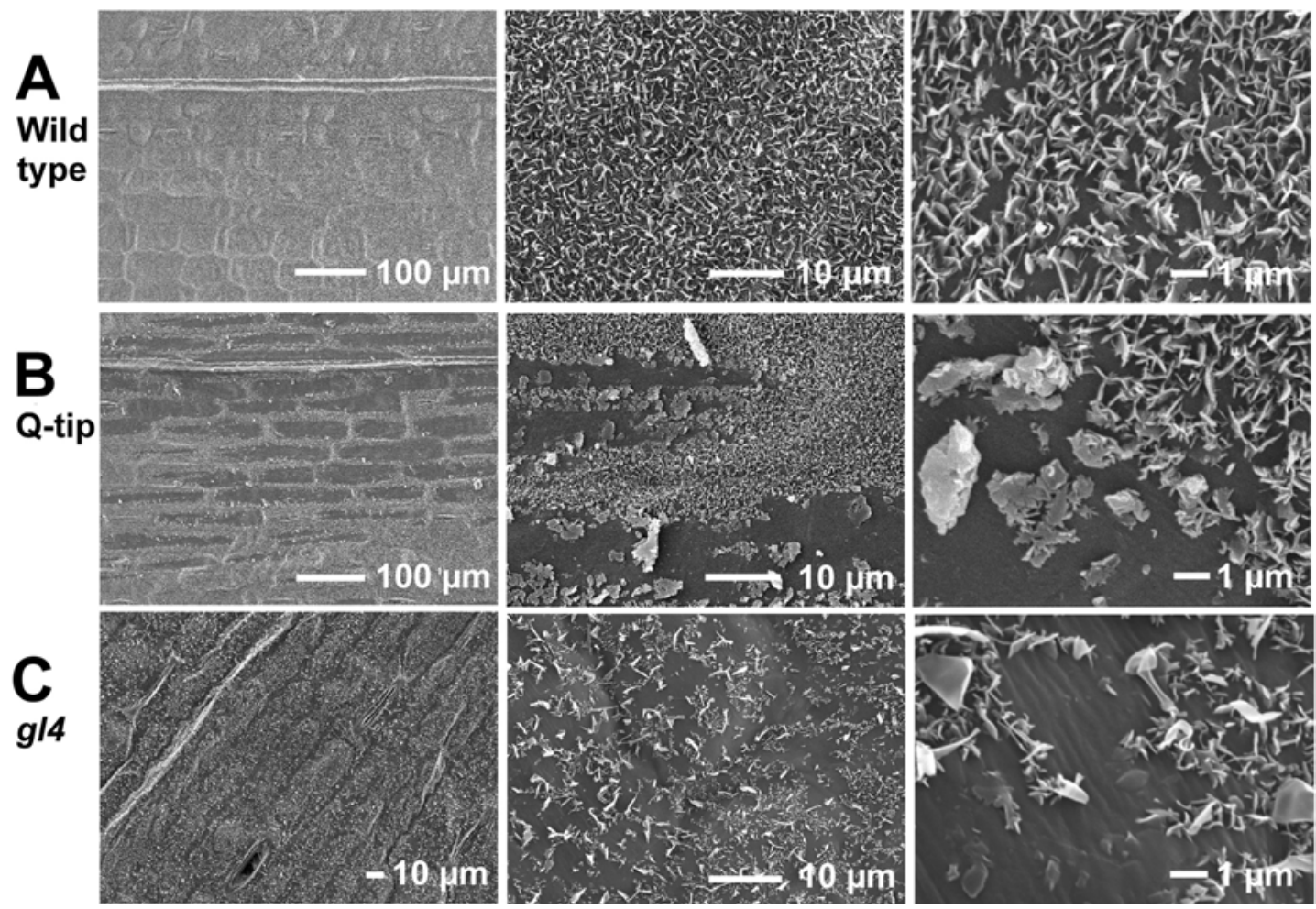

Fig. 5. Scanning electron micrographs of the leaf surface waxes of maize leaves. A, Unaltered wild-type maize. B, Wild type that had been brushed with cotton-tipped applicator sticks (Q-tips). C, Mutant $\mathrm{gl4}$. From left to right, the micrographs are at a magnification of $\times 200$ for $\mathbf{A}$ and $\mathbf{B}$ and $\times 500$ for $\mathbf{C}$; $\times 2,000$ for $\mathbf{A}-\mathbf{C}$; and $\times 10,000$ for $\mathbf{A}-\mathbf{C}$. 
In each experiment, 12 replicate leaves for each strain were harvested immediately following inoculation. Harvested leaves included only the second, third, and fourth leaf of the maize plants. Each leaf was homogenized using a Brinkmann's PT 10-35 homogenizer with a 20-mm generator (Brinkmann Instruments, Inc., Westbury, NY, U.S.A.), and the homogenate was plated for viable counts on the appropriate medium. In the experiment involving both strains, the size of the populations that were recovered following sonication and following subsequent leaf homogenization were determined separately, as described below, and the total number of bacteria associated with the leaf was considered to be the sum of the populations in each the leaf sonicate and the leaf homogenate. The size of the populations recovered in each process was a focus of a separate study (Beattie and Marcell 2002a). All population sizes were expressed as CFU per gram of leaf (fresh weight).

\section{Evaluation of bacterial population dynamics.}

The results of the bacterial retention studies were used to determine the cell density required in the inoculum for each genotype to promote the retention of approximately $10^{6}$ cells per $g$ of leaf. In three experiments to evaluate the population dynamics of $P$. agglomerans BRT98 on maize (designated experiments $\mathrm{P} 1, \mathrm{P} 2$, and $\mathrm{P} 3$ ), the inocula contained the following cell densities: $10^{8}$ cells $/ \mathrm{ml}$ for the wild type, $2 \times 10^{7}$ cells per $\mathrm{ml}$ for $\mathrm{gl}$, and $5 \times 10^{6}$ cells per $\mathrm{ml}$ for $\mathrm{gll}, \mathrm{gl3}$, and $\mathrm{gl} 5 \mathrm{gl} 20$. The BRT98 population sizes on the leaves immediately following inoculation varied 1.9- to 2.7-fold among the genotypes in the three experiments. In one experiment to evaluate the population dynamics of $C$. michiganensis subsp. nebraskensis GH2390 (designated experiment $\mathrm{C} 1$ ), the inocula contained cell densities of $8 \times 10^{8}$ cells per $\mathrm{ml}$ for the wild type, 2 $\times 10^{8}$ cells $/ \mathrm{ml}$ for $g l 4$, and $5 \times 10^{7}$ cells per $\mathrm{ml}$ for $\mathrm{gll}, \mathrm{gl} 3$, and gl5 gl20; whereas, in two other experiments (designated C2 and $\mathrm{C} 3$ ), the inocula contained densities of $2 \times 10^{8}$ cells per $\mathrm{ml}$ for the wild type, $4 \times 10^{7}$ cells per $\mathrm{ml}$ for $\mathrm{gl}$, and $1 \times 10^{7}$ cells per $\mathrm{ml}$ for $g l l, g l 3$, and $g l 5 \mathrm{gl} 20$. The GH2390 population sizes on the leaves immediately following inoculation varied 1.5- to 2.0-fold among the genotypes in the three experiments.

After inoculation, the plants were incubated in an enclosed plastic tent on the laboratory bench for $8 \mathrm{~h}$. The plants then were transferred to a growth chamber and were incubated at $28^{\circ} \mathrm{C}$ and $95 \% \mathrm{RH}$ (range: 75 to $99 \% \mathrm{RH}$ ) with a 12 -h photoperiod for 4 additional days. Twelve replicate leaves, including leaves 2,3 , and 4 , were harvested immediately following in- oculation and at the same time each day for 4 days thereafter. The individual leaves were weighed and placed in test tubes containing $20 \mathrm{ml}$ of washing buffer $(0.1 \mathrm{M}$ potassium phosphate buffer, $\mathrm{pH} 7$, containing $0.1 \%$ peptone) for processing. Three replicate experiments were performed, with the only difference between the experiments being possible differences in the temperature and $\mathrm{RH}$ in the laboratory during the initial 8-h incubation and a difference in the procedure used to estimate the size of the bacterial populations associated with each leaf. In the first two replicate experiments for each strain (experiments P1, P2, C1, and C2), the total number of leaf-associated cells of each strain was determined by enumerating the nonadherent cells, which were those released by sonication, and the adherent cells, which were those released by homogenization, as described previously (Beattie and Marcell 2002a), and then calculating the sum of the nonadherent and adherent cells and reporting this as the total number of leaf-associated cells of that strain. The dynamics of the nonadherent and adherent populations of BRT98 and GH2390 were a focus of a separate study (Beattie and Marcell 2002a). In the third replicate experiment for each strain (experiments P3 and C3), the total number of leaf-associated cells of each strain was directly determined by enumerating the cells in the leaf homogenates. Specifically, the leaves were homogenized using a tissue pulverizer (Kinetic Laboratory Equipment Co., Visalia, CA, U.S.A.), and the homogenate was plated to determine the number of viable cells.

An additional experiment was performed with BRT98 on the wild type and $g l 4$ as described above for experiment P1 with the following exceptions. The inocula contained $10^{9}$ cells per $\mathrm{ml}$ for the wild type and $2 \times 10^{8}$ cells per $\mathrm{ml}$ for $\mathrm{gl}$. After the initial 8-h incubation, the plants were transferred to a plant growth chamber and were incubated at $28^{\circ} \mathrm{C}$ and $45 \% \mathrm{RH}$ (range: 30 to $60 \% \mathrm{RH}$ ) with a $12-\mathrm{h}$ photoperiod.

\section{Evaluation of the effect of mechanical alteration of the wild-type cuticle on bacterial colonization.}

To alter the amount and distribution of the epicuticular wax crystals on leaves 2,3 , and 4 , the adaxial and abaxial surfaces of each leaf were simultaneously subjected to a single, continuous brushstroke with cotton-tipped applicator sticks along the entire length of the leaf. Leaves were subjected to this treatment twice while they were still attached to the plants. During this treatment, extreme care was taken to avoid additional contact with, or injury to, the leaf. The possibility of injury to the leaf was evaluated by excising segments $(0.5$ by $0.5 \mathrm{~cm})$ of

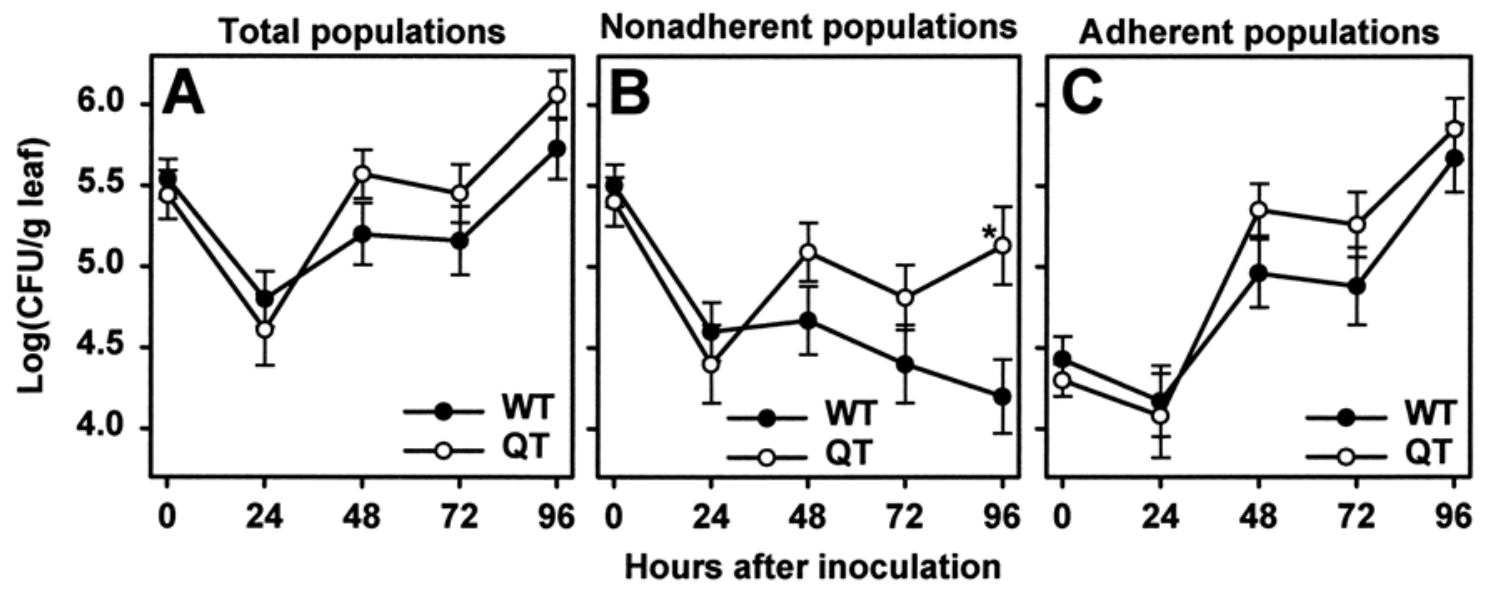

Fig. 6. Colonization of wild-type maize (WT) and mechanically altered maize (QT) by Pantoea agglomerans BRT98. Wild-type leaves were mechanically altered by brushing with a cotton-tipped applicator stick to remove some of the epicuticular crystalline waxes. Each value represents the mean log(CFU/g leaf) \pm standard error of 8 to 12 samples. Populations shown are the A, total populations, B, nonadherent populations, and $\mathbf{C}$, adherent populations. For each sampling time, values indicated by $*$ significantly differed from the mean population on the wild type when compared by a Student's $t$-test $(P<0.05)$. 
leaves 3 and 4 and preparing the leaf segments for, and viewing them by, scanning electron microscopy as described previously (Beattie and Marcell 2002b).

Plants of both the wild type and the wild type following treatment with cotton-tipped applicator sticks (referred to as the mechanically altered leaves) were inoculated with suspensions containing $10^{8}$ cells per $\mathrm{ml}$ for the wild type and $2 \times 10^{7}$ cells per $\mathrm{ml}$ for the wild-type plants with mechanically altered leaves. Sampling and bacterial quantification were performed as described above for experiment P1.

\section{Statistical methods.}

In the experiments evaluating bacterial population dynamics, the population sizes immediately following inoculation were nearly the same on all of the genotypes within an experiment. Although it is unlikely that the small differences in the initial population sizes among the mutants significantly affected the subsequent dynamics of the bacterial populations, these differences potentially could interfere with our ability to estimate true differences in the population dynamics among the mutants and the wild type. Thus, in addition to evaluating population dynamics based on the actual population sizes, we evaluated the dynamics of the populations after normalization to the initial population sizes. Comparisons of these normalized values should more accurately reflect true differences among the plant genotypes in bacterial colonization dynamics. Differences in bacterial population sizes on each mutant versus on the wild type in experiments $\mathrm{P} 1, \mathrm{P} 2$, and $\mathrm{P} 3$ were evaluated using a two-factor analysis of variance (ANOVA) on the population sizes of the leaves of the wild type and the leaves of a mutant sampled at 24, 48, 72, and 96 h using experiment (P1, P2, and P3) and genotype (mutant and wild type) as factors. Differences in bacterial population sizes on a mutant versus on the wild type within an experiment were evaluated by ANOVA. Similar analyses were performed with the data from experiments $\mathrm{C} 1, \mathrm{C} 2$, and $\mathrm{C} 3$. These analyses were performed on both the log-transformed population sizes, following confirmation that the population sizes on the leaves of each genotype were log-normally distributed (Hirano et al. 1982), and on the log-transformed population sizes that had been normalized to the population sizes at $0 \mathrm{~h}$. These analyses were performed using SAS (SAS Institute Inc., Cary, NC, U.S.A.) or Microsoft Excel. The analyses of the nonnormalized and normalized data generally yielded similar results and, when they did not, the differences were clearly attributable to differences in the initial population sizes. Only the statistical analyses of the normalized data are shown and discussed. All other statistical analyses are described in the Results.

\section{ACKNOWLEDGMENTS}

This work was supported by grant 99-35303-8301 from the USDA CSREES National Research Initiative Competitive Grants Program. This is Paper No. J-19414 of the Iowa Agriculture and Home Economics Experiment Station, Ames, Project No. 3588. We thank P. S. Schnable and C. Dietrich for providing the glossy mutant seeds, the North Central Regional Plant Introduction Station for providing wild-type maize seeds, B. Wagner and T. Pepper for their microscopy assistance, L. Carpp for technical assistance, and S. Sabaratnam and C. Axtell for their comments on the manuscript.

\section{LITERATURE CITED}

Barthlott, W., and Neinhuis, C. 1997. Purity of the sacred lotus, or escape from contamination in biological surfaces. Planta 202:1-8.

Beattie, G. A. 2002. Leaf surface waxes and the process of leaf colonization by microorganisms, Pages 3-26 in: Phyllosphere Microbiology. S. E. Lindow, E. I. Hecht-Poinar, and V. J. Elliott, eds. American Phytopathological Society Press, Minneapolis, MN.
Beattie, G. A., and Lindow, S. E. 1999. Bacterial colonization of leaves: A spectrum of strategies. Phytopathology 89:353-359.

Beattie, G. A., and Marcell, L. M. 2002a. Comparative dynamics of adherent and non-adherent bacterial populations on maize leaves. Phytopathology 92:1015-1023.

Beattie, G. A., and Marcell, L. M. 2002b. Effect of alterations in cuticular wax biosynthesis on the physicochemical properties and topography of maize leaf surfaces. Plant Cell Environ. 24:1-16.

Bianchi, A., Bianchi, G., Avato, P., and Salamini, F. 1985. Biosynthetic pathways of epicuticular wax of maize as assessed by mutation, light, plant age and inhibitor studies. Maydica 30:179-198.

Bianchi, G. 1995. Plant waxes, Pages 175-213 in: Waxes: Chemistry, Molecular Biology and Functions. R. J. Hamilton, ed. Oily Press Ltd., Scotland

Bianchi, G., Avato, P., and Salamini, F. 1977. Glossy mutants of maize. VII. Chemistry of glossy 1, glossy 3 and glossy 7 epicuticular waxes. Maydica 22:9-17

Bianchi, G., Avato, P., and Salamini, F. 1978. Glossy mutants of maize. VIII. Accumulation of fatty aldehydes in surface waxes of $\mathrm{gl5}$ maize seedlings. Biochem. Genet. 16:1015-1021.

Bianchi, G., Avato, P., and Salamini, F. 1979. Glossy mutants of maize. IX. Chemistry of glossy 4, glossy 15 and glossy 18 surface waxes. Heredity 42:391-395.

Brandl, M. T., and Lindow, S. E. 1998. Contribution of indole-3-acetic acid production to the epiphytic fitness of Erwinia herbicola. Appl. Environ. Microbiol. 64:3256-3263.

Bunster, L., Fokkema, N. J., and Schippers, B. 1989. Effect of surface-active Pseudomonas spp. on leaf wettability. Appl. Environ. Microbiol. 55:1340-1345.

Clement, J. A., Porter, R., Butt, T. M., and Beckett, A. 1994. The role of hydrophobicity in attachment of urediniospores and sporelings of Uromyces viciae-fabae. Mycol. Res. 98:1217-1228.

Fiala, V., Glad, C., Martin, M., Jolivet, E., and Derridj, S. 1990. Occurrence of soluble carbohydrates on the phylloplane of maize (Zea mays L.): Variations in relation to leaf heterogeneity and position on the plant. New Phytol. 115:609-615.

Haefele, D. M., and Lindow, S. E. 1984. Changes in leaf surface characteristics influence the mean, variance, and nucleation frequency of epiphytic ice nucleation active bacterial populations (Abstr.) Phytopathology 74:882.

Hirano, S. S., Nordheim, E. V., Arny, D. C., and Upper, C. D. 1982. Lognormal distribution of epiphytic bacterial populations on leaf surfaces. Appl. Environ. Microbiol. 44:695-700.

Hirano, S. S., and Upper, C. D. 2000. Bacteria in the leaf ecosystem with emphasis on Pseudomonas syringae - a pathogen, ice nucleus, and epiphyte. Microbiol. Mol. Biol. Rev. 64:624-653.

Hoch, H. C., Staples, R. C., Whitehead, B., Comeau, J., and Wolf, E. D. 1987. Signaling for growth orientation and cell differentiation by surface topography in Uromyces. Science 235:1659-1662.

Jeffree, C. E. 1996. Structure and ontogeny of plant cuticles, Pages 33-82 in: Plant Cuticles: An Integrated Functional Approach. G. Kerstiens, ed. BIOS Scientific Publishers, Oxford.

Jenks, M. A., and Ashworth, E. N. 1999. Plant epicuticular waxes: Function, production, and genetics. Hortic. Rev. 23:1-68.

Marcell, L. M. 2000. The effect of the maize leaf cuticular landscape on bacterial colonization of the phyllosphere. M.S. Thesis. Iowa State University, Ames.

Martin, J. T., and Juniper, B. E. 1970. The Cuticles of Plants. Edward Arnold, Oxford.

Mercier, J., and Lindow, S. E. 2000. Role of leaf surface sugars in colonization of plants by bacterial epiphytes. Appl. Environ. Microbiol. 66:369-374.

Mercure, E. W., Leite, B., and Nicholson, R. L. 1994. Adhesion of ungerminated conidia of Colletotrichum graminicola to artificial hydrophobic surfaces. Physiol. Mol. Plant Pathol. 45:421-440.

Neinhuis, C., and Barthlott, W. 1997. Characterization and distribution of water-repellent, self-cleaning plant surfaces. Ann. Bot. 79:667-677.

O'Brien, R. D., and Lindow, S. E. 1989. Effect of plant species and environmental conditions on epiphytic population sizes of Pseudomonas syringae and other bacteria. Phytopathology 79:619-627.

Ohlrogge, J. B. 1994. Design of new plant products: Engineering of fatty acid metabolism. Plant Physiol. 104:821-826.

Poplawsky, A. R., and Chun, W. 1998. Xanthomonas campestris pv. campestris requires a functional pigB for epiphytic survival and host infection. Mol. Plant-Microbe Interact. 11:466-475.

Rentschler, I. 1971. The wettability of leaf surfaces and the submicroscopic structure of their wax. Planta 96:119-135.

Schnabel, E. L., and Jones, A. L. 1999. Distribution of tetracycline resistance genes and transposons among phylloplane bacteria in Michigan apple orchards. Appl. Environ. Microbiol. 65:4898-4907. 
Schnable, P. S., Stinard, P. S., Wen, T.-J., Heinen, S., Weber, D., Schneerman, M., Zhang, L., Hansen, J. D., and Nikolau, B. J. 1994. The genetics of cuticular wax biosynthesis. Maydica 39:279-287.

Schneider, R. W., and Grogan, R. G. 1977. Tomato leaf trichomes, a habitat for resident populations of Pseudomonas tomato. Phytopathology 67:898-902.

Sundin, G. W., and Jacobs, J. L. 1999. Ultraviolet radiation (UVR) sensitivity analysis and UVR survival strategies of a bacterial community from the phyllosphere of field-grown peanut (Arachis hypogeae L.). Microb. Ecol. 38:27-38.

Thompson, I. P., Bailey, M. J., Fenlon, J. S., Fermor, T. R., Lilley, A. K.,
Lynch, J. M., McCormack, P. J., McQuilken, M. P., Purdy, K. J., Rainey, P. B., and Whipps, J. M. 1993. Quantitative and qualitative seasonal changes in the microbial community from the phyllosphere of sugar beet (Beta vulgaris). FEMS Microbiol. Ecol. 16:205-211.

Vidaver, A. K. 1967. Synthetic and complex media for the rapid detection of fluorescence of phytopathogenic pseudomonads: Effect of the carbon source. Appl. Environ. Microbiol. 15:1523-1524.

Yu, J., Penaloza-Vazquez, A., Chakrabarty, A. M., and Bender, C. L. 1999. Involvement of the exopolysaccharide alginate in the virulence and epiphytic fitness of Pseudomonas syringae pv. syringae. Mol. Microbiol 33:712-720. 